\title{
Erratum to: Computational Meta-Ethics
}

\section{Towards the Meta-Ethical Robot}

\section{Gert-Jan C. Lokhorst}

\section{Erratum to: Minds \& Machines (2011) \\ DOI 10.1007/s11023-011-9229-z}

Under the section heading "Design of a Meta-Ethical Robot", the sentence starting with " $\mathfrak{\Im}_{\mathrm{T}}^{\circ}$ has the same language as the propositional..." should read as below: " $\mathfrak{\Im}_{\mathrm{T}}^{\circ}$ has the same language as the propositional calculus, except that there is an additional unary connective $\square$, read as..."

The online version of the original article can be found under doi:10.1007/s11023-011-9229-z.

G.-J. C. Lokhorst ( $\square)$

Section of Philosophy, Faculty of Technology, Policy and Management, Delft University of Technology, P.O. Box 5015, 2600 GA Delft, The Netherlands

e-mail: g.j.c.lokhorst@tudelft.nl 